\title{
Aspects of testing a large-scale two-span bridge model on multiple shake tables
}

\author{
N. Johnson ${ }^{1}$, M. Saiidi ${ }^{2} \&$ D. Sanders ${ }^{2}$ \\ ${ }^{1}$ Stantec Consulting, USA \\ ${ }^{2}$ Department of Civil and Environmental Engineering, \\ University of Nevada, Reno, USA
}

\begin{abstract}
A quarter scale model of a two-span reinforced concrete bridge was recently tested using the NEES multiple shake table system at the University of Nevada, Reno. The project was funded through a Network for Earthquake Engineering Simulation (NEES) demonstration grant. The prototype was designed using the provisions of the National Cooperative Highway Research Program document 12-49 for seismic design of highway bridges. The input shake table motions included the soil-foundation-structure-interaction effects. The bridge was designed for "life safety". Test results demonstrated that the model met the performance objectives for both earthquakes. Additional analytical studies were conducted to evaluate the bridge model response for design spectra-compatible, synthetic ground motions.

Many important lessons were learned in the course of designing, constructing, testing, data interpretation, and extensive analytical studies that followed. These lessons demonstrated the system effects on individual piers and the structure, ramifications of multi-support excitation testing, performance under design earthquakes, effect of redundancy in the lateral loading system, and the effectiveness of existing analytical models in replicating the response. The presentation and the paper will provide the highlights of the experimental and analytical studies and a summary of important results and conclusions.
\end{abstract}

Keywords: shake table, bridge, earthquake, experimental testing, columns, reinforced concrete, NCHRP 12-49. 


\section{Introduction}

A vast amount of experimental research has been concentrated on broadening technology to calculate the nonlinear response and understanding performance of highway bridges under earthquake loads. Past experiments have primarily focused on components of bridge systems to improve and validate modeling techniques, to test performance of new designs, or to evaluate old designs and to develop retrofit measures to improve response of existing structures that have insufficient details to adequately resist earthquake forces. However, due to limitations of earthquake testing facilities, and because system testing of bridges requires a large scale specimen, system tests have generally not been conducted.

The research that is presented in this document is part of a collaborative PreNEES study to investigate soil-foundation-structure-interaction (SFSI) of bridge systems. Data from this test has been used by research collaborators to integrate the bridge structural response into computer models to study SFSI. The major focus in this research was on the multiple shake table testing of a large scale reinforced concrete bridge system including the analytical modeling of bridges and investigation of bridge system response. Information in this paper presents highlights of the select portions of analytical and experimental studies of the shake table tests. Further information can be found in Johnson et al. [6].

\section{Prototype design}

Seismic detailing of the prototype was based on the Caltrans SDC [4] and NCHRP 12-49 Recommended LRFD Guidelines for the Seismic Design of Highway Bridges [3]. General design of the prototype was based on the American Association of State Highway and Transportation Officials AASHTO LRFD bridge specifications [1] The bridge specimen (fig. 1), which was composed of 11 major components, was designed to model the system interaction between three two-column bridge bents of varying heights. It was created at quarter scale to maximize the size of the specimen while remaining below the capacity of the shake tables.

The total height of the specimen to the top of the superstructure was $3.28 \mathrm{~m}$; the total length was $20.5 \mathrm{~m}$. Span lengths were $9.14 \mathrm{~m}$ and the columns of the three bents had clear heights of $1.83 \mathrm{~m}$ (bent 1), $2.44 \mathrm{~m}$ (bent 2), and $1.52 \mathrm{~m}$ (bent 3) with the tallest bent in the middle. The superstructure was composed of a solid slab that was post-tensioned in both the longitudinal and transverse direction of the bridge. It was designed to maintain generally un-cracked stiffness properties throughout the tests and its stiffness matched the stiffness of the prototype about both bending axes. Due to the scaling effect, masses of the quarter scale model provide a smaller axial stress than in the prototype scale. Some of the required axial load was provided by the self weight of the bridge model. The rest was provided by superimposed dead load that was attached to the top of the superstructure. 


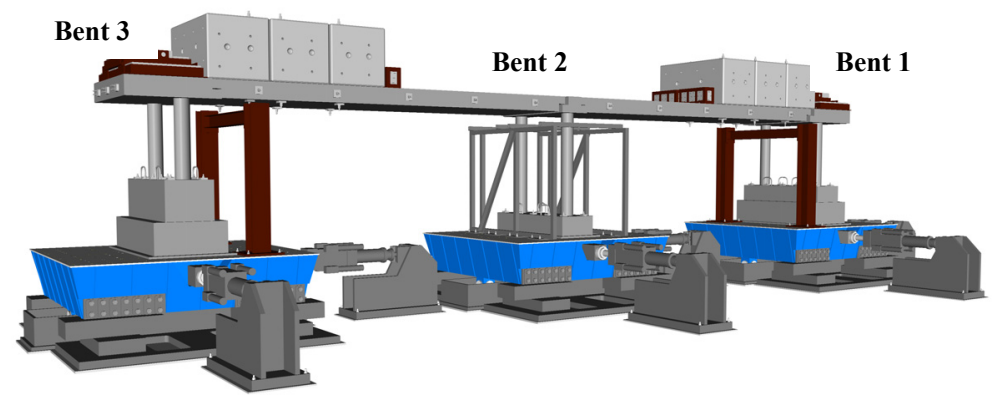

Figure 1: $\quad$ Rendering of bridge model on shake tables.

\subsection{Seismic design}

The demand in the NCHRP design code is site specific. Two performance levels are specified in NCHRP 12-49: life safety and operational. The prototype bridge was considered to be a non-essential (not a critical lifeline) bridge. Therefore the life safety performance level is the level that was considered for the design of the bridge model. Life safety is the minimum performance level that is allowed in the specifications and is intended to protect human life during and after a rare earthquake. For both the rare and expected design earthquakes, two performance level categories must be met for the life safety performance to be satisfied: service level and damage level.

For the expected earthquake, which is what is to be expected during the life of the bridge, the service level that must be satisfied is "immediate" use and the damage level is "minimal". Normal bridge operation can take place after postearthquake bridge inspection. The minimal damage level permits limited damage to the columns including narrow flexural cracking and slight inelastic response. The columns should be completely repairable under non-emergency conditions. For the rare earthquake, which is the maximum considered earthquake, the expected service level is "significant disruption" and the damage level is "significant". Limited post-earthquake access may be possible, however, the bridge may need to be replaced. Cracking, reinforcement yield, and major concrete spalling may take place and replacement of the columns may be necessary. However, the bridge should not collapse.

\subsection{Seismic detailing}

The lateral reinforcement consisted of spiral steel that was continuous throughout the height of the columns. For comparison, the lateral steel was designed using four bridge design codes: NCHRP 12-49 [3], Caltrans SDC [4], AASHTO Standard Specifications [2], and AASHTO LRFD [1]. All of the design codes contain two basic design requirements, confinement reinforcement to increase plastic hinge rotation capacity, and shear reinforcement to prevent shear failure. The spiral reinforcement was first designed based on confinement requirements and then was checked to ensure sufficient shear capacity. 
The design that was implemented in the shake table model was that resulting from NCHRP 12-49. Reinforcement to prevent longitudinal buckling, which could be considered as a type of confinement, controlled the design of all three columns. The amount of reinforcement that was included as spirals in all three sets of the columns provided a lateral reinforcement ratio of 0.009 . For comparison, requirements for confinement controlled all three of the columns considering both of the AASHTO codes, and controlled the tallest column considering the Caltrans SDC. For the short and medium height columns, Caltrans lateral reinforcement requirements were controlled by shear.

Table 1: $\quad$ Shake table tests and achieved bend displacement ductility.

\begin{tabular}{|c|c|c|c|c|}
\hline Test & Target motion $(\mathrm{g})$ & Bent $1 \mu_{\Delta}$ & Bent $2 \mu_{\Delta}$ & Bent 3 $\mu_{\Delta}$ \\
\hline $1-11$ & 0.18 & 0.29 & 0.15 & $\mathbf{0 . 3 7}$ \\
\hline 12 & 0.075 & $\mathbf{0 . 3 5}$ & 0.16 & 0.24 \\
\hline 13 & 0.15 & $\mathbf{0 . 9 5}$ & 0.41 & 0.61 \\
\hline 14 & 0.25 & $\mathbf{1 . 1 3}$ & 0.54 & 0.97 \\
\hline 15 & 0.5 & 2.33 & 1.20 & $\mathbf{2 . 8 6}$ \\
\hline 16 & 0.75 & $\mathbf{3 . 9 3}$ & 2.20 & 3.68 \\
\hline 17 & 1 & $\mathbf{2 . 9 5}$ & 1.87 & 2.79 \\
\hline 18 & 1.33 & 4.14 & 3.23 & $\mathbf{6 . 4 6}$ \\
\hline 19 & 1.66 & 5.25 & 4.10 & $\mathbf{9 . 2 2}$ \\
\hline 20 & 1 & 3.35 & 2.96 & $\mathbf{6 . 8 1}$ \\
\hline
\end{tabular}

\section{Shake table motions}

Both low and high amplitude testing was conducted on the bridge model. Earthquake motions that were used were calculated based on the measured records at the Century City Country Club from the 1994 Northridge, California earthquake. The low amplitude tests included transverse coherent and incoherent, and biaxial coherent target motions (tests 1-11). Low amplitude motions were such that the longitudinal reinforcement in the columns did not yield. High amplitude tests (tests 12-20) were a transverse coherent motion that was applied in increments from a pre-yield demand $(0.075 \mathrm{~g}$ PGA) until bent failure (1.66g PGA) when the shortest of the bents failed in flexure from crushing of confined concrete and buckling of longitudinal reinforcement. After failure of the first bent, an additional $1 \mathrm{~g}$ motion was applied to the bridge (test 20). The additional motion caused only limited additional damage.

\section{Analytical models}

The goal of the analytical modeling was twofold: the first was to determine the validity of contemporary analytical modeling in duplicating the response of the bridge throughout the range of damage states; the second was to develop a computer model to use for further study. 
Both SAP2000 version9 [5] and Drain-3DX [8] were used in the analytical modeling. Standard methods using nonlinear fiber elements were employed to define column nonlinearity using the measured material properties of the bridge. The achieved shake table motions from high amplitude tests were input to the models in order to capture low amplitude through failure response. Because of the achieved motion incoherency, the measured accelerations from the shake tables were filtered and double integrated for input to the computer models.

There are two fundamental differences between the SAP2000 and Drain-3DX models. The first difference is in the nonlinear elements of the columns (described below). The second is in the method of integration used to solve the forces and displacements. The integration method used for SAP2000 was the Newmark beta method using average acceleration and a relative convergence tolerance of $10^{-7}$. Drain-3DX uses a more direct non-iterative method to calculate the structural response through time. Rather than iterating force for convergence, the force error is applied to the next step. This method requires small time step, but is more stable than traditional iterative methods [8]. For similar convergence of results, the Drain-3DX model was approximately 22 times faster.

There are three primary differences between the nonlinear elements of the columns for SAP2000 and Drain-3DX. The first is that the fiber nonlinearity in the SAP2000 model was lumped at the center of each hinge length. For the Drain-3DX model the moment-curvature relationship from the fiber section was integrated over the hinge length which had a parabolic distribution of curvature. The second is that for fibers in the SAP2000 model, all materials were specified with strength degradation upon failure. In the Drain-3DX model, because strength loss is not permitted in the constitutive relationship for steel, strength degradation upon material failure was only specified for the concrete. Therefore, the drain model did not account for rupture of the longitudinal reinforcement. The final difference between the column elements is for the SAP2000 model, bond slip was specified as part of the steel material properties. For the Drain3DX model, a specific zero-length fiber element that explicitly defined bond slip accounted for concrete gap opening in tension, slip of the reinforcement, and compression of concrete into the connection was included at the column ends.

It was concluded that the Drain-3DX results provided the best match to the measured structural response of the model due to a more refined distributed plasticity fiber element and an element that explicitly modeled reinforcement bond-slip. Because of the good correlation with the measured results and more efficient computation of the Drain-3DX model, it was used to conduct parametric studies of the bridge response.

\section{Performance}

\subsection{Measured performance}

The observed and measured response of the shake table bridge model led to two conclusions with regards to performance. The first was that the modeling 
technique that was used for testing was successful. The second is that the columns, which were designed according to contemporary earthquake design code performed well.

The shortest of the columns, which were located in bent 3 and had an aspect ratio of only 2.5 , showed no signs of shear distress from the pre yield state through failure in flexure other than minor shear cracking. The confinement reinforcement in bent 3 provided adequate confinement stress on the concrete and lateral support of the longitudinal reinforcement to delay buckling of the longitudinal reinforcement, so that the bent could reach a displacement ductility of 7.6 (8.9 using pushover calculated yield displacement) before failure.
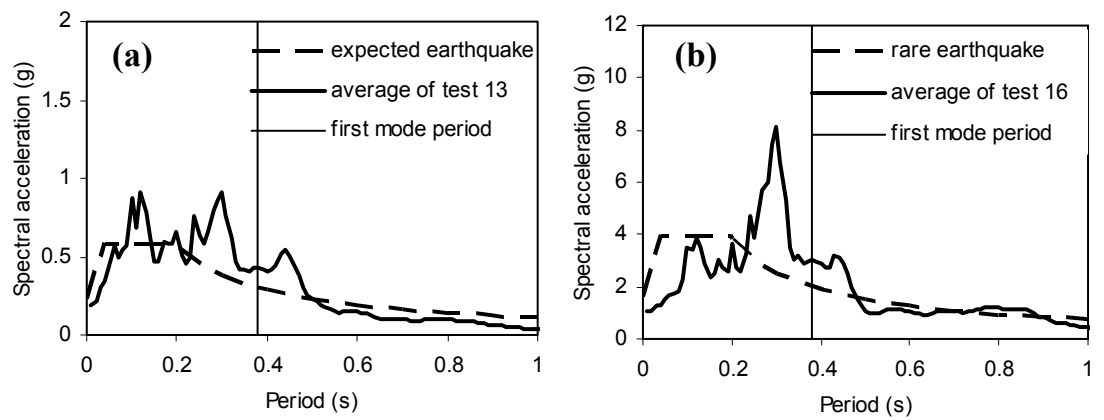

Figure 2: Shake table test motions compared to design spectra for (a) expected event and test 13, and (b) rare event and test 16.

To evaluate the measured response of the shake table bridge model with respect to the design spectra, the tests having achieved shake table accelerations that had approximately the same spectral acceleration at the calculated natural period of the bridge in the transverse direction were determined (fig 2). For test 13 (fig 2(a)), with spectral accelerations that were conservatively equivalent to the amplified expected design earthquake at the first two transverse model frequencies, the maximum displacement ductility was 0.95 in bent 1 . Since none of the bents reached yielding during this test and damage was negligible, the service level performance objective of the NCHRP requirements for the expected earthquake, which was "immediate", as well as the damage level performance objective for the expected earthquake, which was "minimal", were both satisfied. The plastic rotational capacity for the immediate use performance level is 0.01 radians. Based on the curvature measurements from tests, the maximum rotations measured at the plastic hinge regions was only $50 \%$ of the immediate use capacity.

Test 16 (fig 2(b)) was shown by the response spectra to contain spectral accelerations that are conservatively equal to that of the rare design earthquake at the first two transverse modal frequencies of the bridge. All of the bents underwent yielding during test 16. The maximum bent displacement ductility demand was in bent 1, and was 3.31. The failure displacement demand, which was defined as the ratio of maximum displacement over failure displacement for 
each bent was also the largest in bent 1 and was 0.41 . No sign of loss in lateral force capacity was seen, and the column deflections were well below failure. Therefore, life safety performance requirements of the rare event, which were a service level of "significant disruption", and a damage level of "significant", were fulfilled by a relatively high margin. For NCHRP 12-49, the plastic rotational capacity for the life safety performance level can either be calculated from an equation or can be assumed to be 0.035 radians. Based on the curvature measurements from tests the largest ratio measured rotation demand over rotational capacity for the life safety requirement assuming is 0.820 for bent 1 .

\subsection{Analytical performance}

Artificial motions that matched the rare and expected earthquake design spectra were calculated and were input to the Drain-3DX model of the bridge specimen to provide a more direct comparison of the bridge response due to design motions so that the response of the bridge could be compared to the performance criteria.

For the expected event, none of the bents underwent significant yielding. No significant hysteretic energy was dissipated in any of the bents. The largest displacement ductility demand was 1.35 for bent 1 . The largest ratio of the calculated rotational demand over immediate use performance criteria capacity was 0.59 . Since the bents underwent only limited inelastic response and the calculated rotation demands at the column ends were well below the immediate use performance capacity, the bridge performed well and conformed to the performance requirements of the expected design earthquake.

For the rare event, all of bents underwent significant yielding. The largest ratio of displacement demand divided by the calculated ultimate displacement capacity was 0.69 for bent 1 . No sign of reaching the lateral force capacity was calculated, and the column deflections were well below failure displacement. Therefore, the life safety performance requirements of the rare event, which were a service level of "significant disruption" and a damage level of "significant", were satisfied. The largest ratios of the calculated rotational demand over life safety performance criteria using the 0.035 radian capacity and code equation were 0.58 and 0.64 for bent 3 , respectively.

\section{System effects}

\subsection{System vs. individual response}

To determine the system effect on the shake table model, the response of the complete bridge model and individual bents was studied analytically. The Drain-3DX analytical model was used to calculate the response for test motions 13 through 19 of the complete bridge and of the individual bents having tributary mass. This provided a comparison of bent response for component testing on a single shake table, with response from system testing on multiple shake tables. The damage index, which was developed by Park and Paulay [7], 
was the primary method of comparison. It is an empirical measure of damage based on a combination of amount of dissipated hysteretic energy and the maximum displacement demand over ultimate displacement ratio. A damage index of zero indicates no damage; one indicates a high probability of failure.

After yielding, each of the three bents followed a general trend of system vs. individual damage. The system damage index demand in bent 1 exceeded the individual demand by as much as $41 \%$. In bent 2 , the system damage index demand was less than the individual demand by as much as $38 \%$. The damage index demands for system and individual response were approximately the same for bent 3 with a maximum system demand difference of $8.4 \%$ after yielding.

\subsection{Additional systems studied}

Four additional systems having a constant stiffness index (sum of lateral column stiffness) were analyzed using the Drain-3DX model and compared to the system response of the shake table model. The aspect ratios of the columns were within the same range as those tested on the shake tables. The systems included a system with uniform column height, symmetric with a stiff center bent, a symmetric version of the test specimen, and an asymmetric system with a stiff center bent. For comparison, both displacement ductilities and damage indices were calculated for the system and individual bent response of the models subjected to both the rare and expected design motions.

Significant system effects were apparent in the bridges that were analyzed. The maximum system/individual damage ratio on the five systems for the expected earthquake motion, which placed demands on the columns in the systems near column yielding, was 1.57 . The maximum system/individual ratio for the rare motion, which imposed demands far greater than yielding in the columns, was 1.32 .

\subsection{System redundancy}

The failure of an interchange bridge at junction of I5-SR14 during the 1994 Northridge was caused by large variation among the column heights that led to high concentration of shear in one of the columns and its failure. This led to the conclusion that to avoid this type of behavior, the column heights need to be the same in the replacement bridge [9]. Many bridge designers tend to follow a design methodology for earthquake resistant bridges to design a bridge so that if possible it is symmetric and uniform to avoid irregular system response. Therefore it is desirable to design bridges that have uniform column height. As long as earthquake demands on the columns for this type of bridge do not fail the columns, the bridge remains intact. However, if the columns reach their failure displacement, then the entire system will fail due to lack of substructure redundancy.

A comparison was made between calculated ductility demands on the columns for the uniform height bridge and shake table bridge specimen for the test motions for the design motions (expected and rare), respectively. For the rare design motion, the maximum displacement ductility demands on the 
specimen and uniform systems are 5.59 and 5.35, respectively. The specimen has a maximum displacement ductility demand that is approximately $5 \%$ larger than that of the uniform system. It should be noted that there was only a $5 \%$ increase in displacement ductility demand from the rare design earthquake for the non-symmetric system (in comparison to the uniform case), which was shown in tests to provide redundancy in column capacity after failure of the most critical bent. Although this study was limited it does suggest that providing redundancy by varying the column heights might be a better alternative than making the column heights the same.

\section{Conclusions}

The following are conclusions from the selected portions of experimental and analytical studies that were presented in this paper.

(1) The amount of lateral reinforcement provided by the NCHRP 12-49 that is recommended for preventing global buckling of longitudinal reinforcement in the plastic hinge zone was adequate to prevent buckling until large displacement ductility was reached.

(2) The flexural failure of the column with the smallest aspect ratio (2.5) showed that the Caltrans and NCHRP 12-49 seismic detailing requirements for shear reinforcement were adequate.

(3) The bent with the shortest columns failed when the bridge was subjected to a 1.66 PGA ground motion. Although this bent had failed, the remaining two still provided sufficient redundancy and capacity to withstand a $1.0 \mathrm{~g}$ PGA motion that followed.

(4) Available analysis tools using conventional methods were successful in estimating the nonlinear response of a concrete bridge structure with flexure dominated columns from the pre-yield state up to failure. The Drain-3DX model which explicitly included bond slip and incorporated a more efficient integration method better matched measured results and was therefore used for further study.

(5) Analytical modeling using the design motions showed that the maximum column ductility demand for the rare design earthquake was merely $5 \%$ larger for the specimen than for a uniform height column system. This small increase is offset considerably by the increased redundancy of a system with variable height columns.

(6) For the bridge that was tested in this study, system effects did not increase the amount of hysteretic energy dissipation or large displacement cycles on the columns for given values of achieved displacement. However, for specific motions, the system effect caused significant differences in damage to the bents. For post yield motions, the system effect on the damage indices ranged from a decrease of $39 \%$ to an increase of $41 \%$. 


\section{Acknowledgements}

This research was sponsored by the National Science Foundation through NEES award number CMS-0324326. The NSF program directors were Steven McCabe and Joy Pauschke. The study was part of a multi-institution project under the overall direction of Sharon Wood of the University of Texas, Austin. The authors are indebted to the dedicated support of Patrick Laplace and Paul Lucas of the UNR structures lab in the course of the shake table studies.

\section{References}

[1] AASHTO LRFD Bridge Design Specifications. AASHTO, Washington D.C., 1998.

[2] AASHTO Standard Specifications for Highway Bridges, $17^{\text {th }}$ edition. AASHTO, Washington D.C., 2002.

[3] ATC/MCEER Recommended LRFD Guideline for the Seismic Design of Highway Bridges (2001) Part 1: Specifications, MCEER-02-SP01, MCEER/ATC joint venture, NCHRP 12-49 Project Team., 2001.

[4] Caltrans (California Department of Transportation), Caltrans Seismic Design Criteria Version 1.3. Engineering Service Center, Earthquake Engineering Branch, California, 2004.

[5] CSI, Inc., "SAP2000 Linear and Nonlinear Static and Dynamic Analysis and Design of Three-Dimensional Structures," version 9. Berkeley, CA., 2005.

[6] Johnson, N., Saiidi, M., and Sanders, D., "Large-Scale Experimental and Analytical Seiemic Studies of a Two-Span Reinforced Concrete Bridge System", Civil Engineering Department, University of Nevada, Reno., 2006.

[7] Park, R., and Paulay, T., "Reinforced Concrete Structures," Wiley Interscience, 1975.

[8] Prakash, V., and Campbell, S. "Drain-3DX: Static and Dynamic Analysis of Inelastic 3D Structures", Department of Civil Engineering, University of California, Berkeley, 1994.

[9] Saiidi, M., R. Moore, and A. Itani, "Seismic Performance of Reinforced Concrete Bridges With Un-Conventional Configurations," American Concrete Institute, Structural Journal, pp. 717-726, September, 2001. 